\title{
Endocrine changes before and after weaning in response to boar exposure and altered suckling in sows*
}

\author{
E. A. Newton†, J. S. Stevenson, J. E. Minton and D. L. Davis \\ Department of Animal Sciences and Industry, Kansas State University, Manhattan, Kansas 66506, \\ U.S.A.
}

\begin{abstract}
Summary. Eighteen sows (6 primiparous and 12 multiparous) were allotted randomly within parity to two lactational treatments: litter separation (LS; $6 \mathrm{~h} /$ day) plus boar exposure (BE; $1 \mathrm{~h} /$ day; $\mathrm{N}=14$ ) beginning 8 days before weaning (4 weeks) and no $\mathrm{LS}+$ no BE (controls; $\mathrm{N}=4$ ). Blood was collected from all sows via indwelling venous catheters at 20 -min intervals for $5 \mathrm{~h}$ on Days $-1,0,1,2$ and 3 from start of treatment. Control sows and those exposed to $\mathrm{LS}+\mathrm{BE}$ not exhibiting oestrus during lactation were resampled on Days $-1,0,1$ and 2 from weaning. All 10 multiparous sows receiving LS $+\mathrm{BE}$ exhibited oestrus during lactation, whereas none of the 4 primiparous sows exposed to LS $+\mathrm{BE}$ or the 2 control multiparous and 2 control primiparous sows exhibited lactational oestrus. Overall concentrations of $\mathrm{LH}$ in serum were higher $(P<0.05)$ in sows receiving LS + BE than in control sows during lactation, whereas overall FSH was higher $(P<0.05)$ in primiparous than multiparous sows. Number and amplitude of pulses of $\mathrm{LH}$ were greater $(P<0.05)$ for treated primiparous than multiparous sows during lactation. Oestradiol-17 $\beta$ increased $(P<0.05)$ in sows during LS $+\mathrm{BE}$ and was higher $(P<0.01)$ in multiparous sows of this group than control multiparous or treated primiparous sows. Preweaning concentrations of cortisol and progesterone in serum were higher $(P<0.05)$ in treated than control sows for multiparous and primiparous animals.

In sows resampled at weaning, the number of pulses of LH was greater $(P<0.05)$ in treated primiparous than in control sows. Postweaning concentrations of FSH in serum were unaffected by preweaning treatments. It was concluded that (1) litter separation and boar exposure increased basal and pulsatile secretion of LH in multiparous and primiparous sows; (2) lack of ovarian follicular development and oestradiol secretion may preclude expression of oestrus in primiparous sows during lactation, despite elevated concentrations of FSH and LH in serum; and (3) if elevated concentrations of cortisol and progesterone inhibit the onset of oestrous cycles, in response to litter separation and boar exposure during lactation, the effect is limited to primiparous sows.
\end{abstract}

\section{Introduction}

The domestic sow generally remains anoestrous during the first 4-6 weeks of lactation unless patterns of suckling are altered or disrupted (Britt, 1986). Grouping sows and their piglets at 2-3 weeks post partum (Rowlinson \& Bryant, 1981, 1982) or altering patterns of suckling by sow and litter separation for 3,6 or $12 \mathrm{~h}$ /day plus $1 \mathrm{~h}$ of boar exposure (Stevenson \& Davis, 1984; Newton et al., 1987) induced

\footnotetext{
*Reprint requests to Dr J. S. Stevenson.

†Present address: Department of Animal Science, Ohio State University, Columbus, OH 43210, U.S.A.
} 
lactational oestrus in most lactating sows. The endocrine events associated with lactational anoestrus are attributed to the suckling-induced suppression of gonadotrophin secretion. Concentrations of luteinizing hormone ( $\mathrm{LH})$ and follicle-stimulating hormone (FSH) are low during the first 1-2 weeks of lactation, but undergo slight ( $\mathrm{LH}$ ) to significant (FSH) increases during progressive weeks of lactation (Parvizi et al., 1976; Stevenson et al., 1981). Edwards \& Foxcroft (1983) further demonstrated that $\mathrm{LH}$ is released in discrete pulses in some sows during lactation. Secretion of $\mathrm{LH}$ is controlled primarily by suckling intensity of the litter, whereas FSH is probably controlled by a non-steroidal ovarian factor (Stevenson et al., 1981; Britt et al., 1985) and ovarian follicular development during early lactation is suppressed, with most follicles being $<5 \mathrm{~mm}$ in diameter. However, factors such as nutrition, season, boar exposure, litter size and altered suckling influence follicular development, probably because they alter secretion of LH (Britt et al., 1985).

We have demonstrated that when sows are removed from their litters for 3,6 or $12 \mathrm{~h} /$ day for 8 days before weaning and exposed to boars, about $67 \%$ of the sows expressed fertile oestrus in 4-8 days (Stevenson \& Davis, 1984; Newton et al., 1987). In those studies, $3 \mathrm{~h}$ of litter separation and $1 \mathrm{~h}$ of boar exposure were sufficient to induce a lactational oestrus. Furthermore, the oestrous response is markedly age- or parity-dependent because 45,70 and $84 \%$ of the sows in their first, second and third or greater lactation showed oestrus before weaning. Endocrine patterns during altered suckling and boar exposure in sows have not been characterized. However, Duggan et al. (1982) attempted to characterize the endocrine changes of sows grouped together with their litters and mature boars after Day 16 post partum. They reported that concentrations of LH (not FSH) increased 3-fold during the 10-day period after grouping compared with 10 days before grouping. Our objectives were to determine the changes in $\mathrm{LH}, \mathrm{FSH}$, oestradiol-17 $\beta$, progesterone and cortisol associated with altered suckling and boar exposure during lactation and after weaning in primiparous and multiparous sows.

\section{Materials and Methods}

\section{Treatments and animal management}

Beginning 8 days before weaning ( 4 weeks), 12 multiparous and 6 primiparous crossbred (Yorkshire $\times$ Duroc) sows were allotted randomly within parity to two treatments: litter separation (LS, $6 \mathrm{~h} /$ day) plus boar exposure (BE, $1 \mathrm{~h} /$ day; $N=14$ ) or no $\mathrm{LS}+$ no $\mathrm{BE}$ (controls, $\mathrm{N}=4$ ). Multiparous $(\mathrm{M})$ and primiparous $(\mathrm{P})$ sows in the $\mathrm{LS}+\mathrm{BE}$ group were designated as treated (TM and TP) sows, whereas multiparous $(N=2)$ and primiparous $(N=2)$ sows not separated from their litters nor exposed to boars during lactation were designated as controls (CM and $\mathrm{CP}$ ). Indwelling catheters were inserted non-surgically (Ford \& Maurer, 1978) into the vena cava of each sow 3 days before treatment was begun at an average of $19 \pm 2$ days post partum. The number of nursing piglets was standardized to 7-10 piglets within $48 \mathrm{~h}$ after birth. Sows were confined to farrowing crates during lactation except during periods of treatment and were fed ad libitum at 08:00 and 17:00 $\mathrm{h}$ a milo-soybean meal diet (14\% protein) balanced for protein and energy plus supplemental vitamins, minerals, and salt to meet NRC (1979) requirements for lactating sows. Sows were only fed once daily at $08: 00 \mathrm{~h}$ after weaning. Sow and litter weights were recorded $\mathrm{l}$ day before treatment began and at weaning to determine treatment effects on weight changes during lactation. During separation from their litters, sows were moved $(10: 00 \mathrm{~h}$ ) from their farrowing crates to adjacent outside pens. A mature boar ( $>1$ year old) was placed in the pen for $1 \mathrm{~h}$ during which time sows were observed for oestrus. Sows were returned to their litters at 16:00 h.

\section{Scheme for blood collection}

Blood was collected from sows at 20-min intervals from 12:00 to 17:00 h on Days -1, 0, 1, 2 and 3 from treatment (i.e. sampling began $2 \mathrm{~h}$ after litter separation + boar exposure and continued $1 \mathrm{~h}$ after sows were reunited with piglets). Control (2 $\mathrm{CM}$ and $2 \mathrm{CP}$ ) and $4 \mathrm{TP}$ sows not detected in oestrus during lactation were subjected to an identical sampling regimen on Days $-1,0,1$ and 2 from weaning. On Day -1 before weaning, sows were sampled in their farrowing crates $(\mathrm{CM}+\mathrm{CP})$ or in outside pens (TP). On Days 0,1 and 2 after weaning, sows were moved from their farrowing crates, exposed to a mature boar for $1 \mathrm{~h}$ from 11:00 to $12: 00 \mathrm{~h}$ and blood was collected from 12:00 to 17:00 $\mathrm{h}$ as described above. Blood was kept on ice following collection and then held at $5^{\circ} \mathrm{C}$ for $24 \mathrm{~h}$ when serum was obtained by centrifugation. Serum was frozen at $-20^{\circ} \mathrm{C}$ until assayed. All individual samples of serum (16/day) from 18 sows before weaning and 8 sows after weaning were radioimmunoassayed for LH and FSH. Daily pools of serum from each of the 16 samples/sow for the 18 sows before weaning (Days $-1,0,1,2$ and 3 from litter separation + boar exposure) and 8 sows after weaning (Days $-1,0,1$ and 2 from weaning) were radioimmunoassayed for oestradiol-17 $\beta$, progesterone and cortisol. 


\section{Hormone assays}

$L H$. Concentrations of $\mathrm{LH}$ in serum were determined by a double-antibody radioimmunoassay (RIA) similar to that described by Kraeling et al. (1982) with modifications. Purified pig LH (USDA-pLH-1-1, 2.5 $\mu \mathrm{g}$ ) was reacted with $15 \mu \mathrm{g}$ chloramine- $\mathrm{T}$ and $500 \mu \mathrm{Ci}^{125} \mathrm{I}$. The reaction was stopped with $60 \mu \mathrm{g}$ sodium metabisulphite and ${ }^{125} \mathrm{I}$-labelled pig LH was separated from free ${ }^{125} \mathrm{I}$ by anion exchange (AG $2 \times 8$, chloride form, $100-200$ mesh: BioRad Laboratories, Richmond, CA, U.S.A.) and gel filtration chromatography (Bio-Gel P-60, 100-200 mesh; BioRad Laboratories). For the assay, a large pool of pig serum was filtered through a hollow fibre filter system (Amicon Corp., Danvers, MA, U.S.A.) to remove pituitary hormones (exclusion limit $M_{\mathrm{r}} \geq 10000$ ). Albumin from chicken eggs (Sigma Chemical Company, St Louis, MO, U.S.A.) was added to the pool of filtered serum to give a $5 \%(\mathrm{w} / \mathrm{v})$ solution (EA-FPS). Standard curves were prepared in EA-FPS to give 0.05-10 ng USDA-pLH-1-1/200 $\mu$ l EA-FPS. Binding of ${ }^{125}$ Ilabelled pig LH to antisera was similar for tubes containing $200 \mu \mathrm{l}$ EA-FPS plus $300 \mu \mathrm{l}$ assay buffer $(0 \cdot 1 \mathrm{M}$-phosphatebuffered saline with $1 \%$ bovine serum albumin, $\mathrm{pH} 7.5$ ) and for tubes with $500 \mu \mathrm{l}$ assay buffer. The antiserum (Chemicon International, Inc., El Segundo, CA, U.S.A.) did not cross-react significantly with USDA-pGH-B-1 (2.1\%), USDApFSH-B-1 $(0.2 \%)$, or USDA-pPRL-B-1 $(<0.06 \%)$. Increasing volumes of sow serum displaced ${ }^{125}$ I-labelled pig LH from the antiserum to produce a binding curve that was parallel to the standard curve. When $0 \cdot 3,0 \cdot 6,1 \cdot 2,2 \cdot 5,5 \cdot 0$ and $10.0 \mathrm{ng}$ USDA-pLH-I-1/ml were added to EA-FPS, $0.3,0.4,1.2,2.4,5.9$ and $12.4 \mathrm{ng}$, respectively, were recovered (average $99.2 \%$ recovery). Sensitivity of the assay was $0.06 \mathrm{ng} /$ assay tube. All samples were quantified in 5 assays and the intra- and interassay coefficients of variation were $9.4 \%$ and $11.6 \%$ respectively.

FSH. Concentrations of FSH in pig serum were determined by a double-antibody RIA similar to that described by Kraeling et al. (1982) for pig LH. Purified pig FSH (LER-1419-3, 2.5 $\mu \mathrm{g}$ ) was reacted with $10 \mu \mathrm{g}$ chloramine-T and $500 \mu \mathrm{Ci}^{125} \mathrm{I}$. The reaction was stopped with $40 \mu \mathrm{g}$ sodium metabisulphite and ${ }^{125} \mathrm{I}$-labelled pig FSH was separated from free ${ }^{125} \mathrm{I}$ as described above for ${ }^{125} \mathrm{I}$-labelled pig LH. Albumin from bovine serum (Sigma Chemical Co.) was added to filtered pig serum to give a $5 \%(\mathrm{w} / \mathrm{v})$ solution (BSA-FPS). Standard curves were prepared in BSA-FPS ranging from $0 \cdot 128$ to $32.0 \mathrm{ng}$ LER-1419-3/200 $\mu$ l BSA-FPS. Binding of ${ }^{125}$ I-labelled pig FSH to antiserum was similar for tubes containing $200 \mu \mathrm{l}$ BSA-FPS plus $300 \mu \mathrm{l}$ assay buffer $(0.1 \mathrm{M}$-phosphate-buffered saline with $1 \%$ bovine serum albumin, $\mathrm{pH} 7.5$ ) and for tubes with $500 \mu \mathrm{l}$ assay buffer. The antiserum (Chemicon International, Inc.) did not cross-react significantly $(<0 \cdot 1 \%)$ with USDA-pLH-I-1, USDA-pPRL-B-1, or USDA-pGH-B-1. Increasing volumes of sow serum displaced ${ }^{125} \mathrm{I}$-labelled pig FSH from the antiserum to produce a binding curve that was parallel to the standard curve. When $1,2,4,8,16$ and $32 \mathrm{ng}$ LER-1419-3/ml were added to BSA-FPS, $0 \cdot 8,1 \cdot 6,4 \cdot 3,9 \cdot 6,18 \cdot 4$ and $34 \cdot 2 \mathrm{ng}$, respectively, were recovered (average $101 \cdot 6 \%$ recovery). Sensitivity of the assay was $0.256 \mathrm{ng} / \mathrm{assay}$ tube. All samples were quantified in 5 assays and the intra- and inter-assay coefficients of variation averaged $3 \cdot 8 \%$ and $12 \cdot 1 \%$, respectively.

Progesterone. Concentrations of progesterone in pig serum were determined by RIA according to previously described procedures using a highly specific progesterone antiserum (Stevenson et al., 1981). The antiserum was obtained by immunizing rabbits against progesterone-11-hemisuccinate-BSA (Q3253, Steraloids, Inc., Wilton, NH, U.S.A.). Standard progesterone (P0130, Sigma Chemical Co.) in $95 \%$ ethanol only cross-reacted ( $>1 \%$ ) with $17 \alpha-$

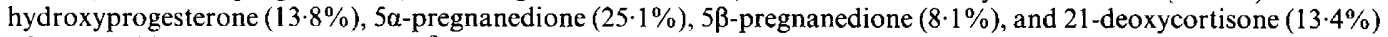
of 19 steroids tested. $\left[1,2,6,7,16,17-{ }^{3} \mathrm{H}\right]$ Progesterone (TRK.621, Amersham, Chicago, IL, U.S.A.) was repurified by Sephadex LH20 (Pharmacia, Uppsala, Sweden) column chromatography using iso-octane:benzene $(90: 10, \mathrm{v} / \mathrm{v})$ as column solvents. Extraction of $\left[{ }^{3} \mathrm{H}\right]$ progesterone from pig serum averaged $81 \%$ in 10 assays. Progesterone was recovered quantitatively when added to serum $(r=0.99)$ and increasing volumes of pig serum displaced $\left[{ }^{3} \mathrm{H}\right]$ progesterone from a binding curve that paralleled the standard curve. Various volumes $(n=4)$ of pig serum $(25,50$ and $75 \mu 1)$ measured $24.7,21.9$ and $19.4 \mathrm{ng} / \mathrm{ml}$, respectively. Sensitivity of the assay was $20 \mathrm{pg} /$ tube. All samples were quantified in two assays and the intra- and interassay coefficients of variation averaged $9.7 \%$ and $10.7 \%$, respectively.

Oestradiol. Concenrations of oestradiol-17 $\beta$ in pig serum were quantified in 4 assays according to previously described procedures (Kluber et al., 1985). Samples of serum (6 $\mathrm{ml}$ in duplicate) were extracted twice with ethyl acetate with extraction efficiency averaging $85 \%$ in 4 assays. The antiserum (oestradiol-6-3: N. R. Mason, Eli Lilly and Company, Indianapolis, IN, U.S.A.) was highly specific for oestradiol-17ß. Cross-reactivities with oestradiol-17 $\alpha$, oestrone, oestriol, testosterone, and androstenedione were $<0 \cdot 01 \% \cdot\left[2,4,6,7-{ }^{3} \mathrm{H}\right]$ Oestradiol- $17 \beta$ (TRK.322, Amersham) was used as assay tracer and oestradiol-173 (E-8875, Sigma Chemical Co.) in $95 \%$ ethanol as the standard. Addition of 25,50 or $100 \mathrm{pg}$ oestradiol-17ß $(n=4 \mathrm{each})$ to pig serum yielded 28,49 and $97 \mathrm{pg}$, respectively $(r=0 \cdot 98)$. Increasing volumes of pig serum displaced $\left[{ }^{3} \mathrm{H}\right]$ oestradiol- $17 \beta$ from a binding curve that paralleled the standard curve. Sensitivity of the assay was $5 \mathrm{pg} /$ tube. The intra- and interassay coefficients of variation averaged $8.3 \%$ and $11.1 \%$ respectively.

Cortisol. Cortisol in serum was measured in 3 RIAs using a specific antiserum obtained from immunizing rabbits against cortisol-3-hemisuccinate-BSA (Western Chemical, Fort Collins, CO, U.S.A.). Specificity of the antiserum was tested against 14 different steroids and it only cross-reacted slightly (at $50 \%$ binding inhibition of the labelled cortisol) with 11-deoxycortisol $(7.5 \%)$, cortisone $(0.6 \%)$, and progesterone $(2.4 \%)$. Crossreactivity was $<0.1 \%$ with corticosterone, deoxycorticosterone, 21 -deoxycortisone, $11 \alpha$-hydroxyprogesterone, $11 \beta$-hydroxyprogesterone,

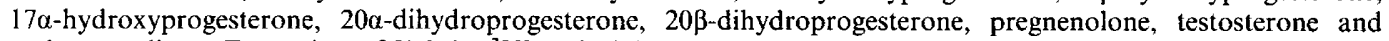
androstenedione. Extraction of $\left[1,2,6,7-{ }^{3} \mathrm{H}\right]$ cortisol (TRK.407, Amersham) from pig serum with ethyl acetate was $88.5 \%$ in 3 assays. When $50,60,80,100,120,160,200,400$ and $600 \mathrm{pg}$ standard cortisol (H-4001, Sigma Chemical Co.) were added to $0 \cdot 1 \mathrm{ml}$ pig serum, cortisol recovered was $58,61,75,94,124,164,223,398$ and $569 \mathrm{pg}(r=0.99)$, respectively. Increasing volumes of pig serum displaced $\left[{ }^{3} \mathrm{H}\right]$ cortisol from a binding curve that paralleled the standard 
curve. Various volumes of serum $(0 \cdot 075,0 \cdot 1,0 \cdot 15,0 \cdot 2 \mathrm{ml}, n=4$ each $)$ measured $9 \cdot 9,10 \cdot 6,9 \cdot 5 \mathrm{and} 8 \cdot 5 \mathrm{ng} / \mathrm{ml}$, respectively. Assay sensitivity was $20 \mathrm{pg} /$ tube and intra- and interassay coefficients of variation were $10 \cdot 9 \%$ and $11 \cdot 3 \%$ respectively.

Definitions A rise in the concentration of $\mathrm{LH}$ was defined as a pulse using criteria previously established (Riley et al., 1981; Mcleod et al., 1982). An increase in serum LH was designated as a pulse when (1) the highest LH concentration attained was $50 \%$ above the preceding nadir; (2) at least 2 consecutive LH concentrations ( 20 min apart) were between the peak value and the following nadir value; and (3) the rate of decline from LH peak values was not greater than the half-life of LH, which is $\sim 30 \mathrm{~min}$ in pig serum (Esbendshade et al., 1986). Overall LH was defined as the average of all concentrations of LH within a sow bleeding period ( 1 day), whereas baseline concentrations of LH were equivalent to the average of all concentrations of $\mathrm{LH}$ within a period after excluding peak values (all concentrations contributing to a pulse). Magnitude of LH pulses was defined as the highest value within a pulse, whereas amplitude of LH pulses was obtained by subtracting the baseline concentrations of LH from the magnitude of the pulse of LH. Duration of LH pulses was defined as the interval from nadir to nadir.

\section{Statistical analyses}

Data were subjected to analysis of variance using the General Linear Model procedures of the Statistical Analysis System (SAS, 1982). Hormonal concentrations were analysed as split-plot analyses for repeated measurements. Analysis of variance for all hormonal data included treatment $(n=4)$, sow within treatment, day, and treatment $\times$ day interactions for Days 0, 1,2 and 3(Gill \& Hafs, 1971). Treatment was tested by the between-sow variance (sow within treatment). Analyses of hormonal concentrations on the day before treatment (Day -1) allowed direct contrasts of parity in which data were analysed by one-way analysis of variance (steroid hormones) or by split-plot analysis of variance ( $\mathrm{LH}$ and $\mathrm{FSH}$ ) for repeated measurements (Gill \& Hafs, 1971). Similar analyses of parity were made for the day before weaning. To test effects of parity, the model consisted of parity (primiparous $v s$ multiparous), sow within parity, sample, and sample $\times$ parity interaction. Parity was tested by the between-sow variance (sow within parity). Preplanned contrasts were made to compare treatments: control multiparous (CM) sows with treated multiparous (TM) sows, and control primiparous (CP) vs treated primiparous (TP) sows. Other traits (days to oestrus, lactation, length, litter size, and sow and litter weights at weaning) were analysed by one-way analysis of variance with treatment as the only source of variation. Other comparisons among treatment means were made by Scheffe's interval (Gill, 1978).

\section{Results}

Days post partum at the onset of treatment, litter size, and weight of litters at weaning were similar among treatment groups (Table 1). As expected, multiparous sows were heavier $(P<0.05)$ than primiparous sows. All of the TM sows (10/10) exhibited oestrus during lactation, whereas none of the TP $(0 / 4), C M(0 / 2)$, or CP $(0 / 2)$ sows expressed oestrus until after weaning. Days from treatment $(\mathrm{LS}+\mathrm{BE})$ to oestrus were shorter $(P<0.01)$ for TM sows that expressed oestrus during lactation, whereas intervals to oestrus after weaning for the remaining groups were similar,

Table 1. Sow and litter characteristics after litter separation (LS) and boar exposure (BE) during lactation and at weaning

\begin{tabular}{|c|c|c|c|c|}
\hline & \multicolumn{4}{|c|}{ Treatment group $\dagger$} \\
\hline & $\mathrm{CM}$ & TM & $\mathrm{CP}$ & TP \\
\hline No. of sows & 2 & 10 & 2 & 4 \\
\hline Days post partum before $\mathrm{LS}+\mathrm{BE}$ & $19 \pm 0.9$ & $19 \cdot 6 \pm 1 \cdot 3$ & $18.5 \pm 4.9$ & $17.5 \pm 1.9$ \\
\hline Litter size (nursing piglets/sow) & $7.5 \pm 0.7$ & $8 \cdot 0 \pm 1 \cdot 1$ & $8.5 \pm 4.9$ & $7 \cdot 0 \pm 0.5$ \\
\hline Litter weight at weaning $(\mathrm{kg})$ & $52.7 \pm 5.9$ & $56 \cdot 5 \pm 2 \cdot 7$ & $55.9 \pm 5.9$ & $49 \cdot 3 \pm 4 \cdot 5$ \\
\hline Sow weight $(\mathrm{kg})$ & $183.3 \pm 13 \cdot 5^{*}$ & $187.9 \pm 6 \cdot 3^{*}$ & $160.8 \pm 13.6$ & $166 \cdot 0 \pm 10 \cdot 3$ \\
\hline No. of sows exhibiting oestrus & $\overline{0}$ & $\overline{10}$ & $\overline{0}$ & $\overline{0}$ \\
\hline Days to oestrus from LS + BE & $11 \cdot 0 \pm 0.5$ & $5 \cdot 2 \pm 0 \cdot 5^{* *}$ & $12 \cdot 0 \pm 0.5$ & $13 \cdot 0 \pm 0.3$ \\
\hline Days to oestrus from weaning & $3.0 \pm 0.5$ & & $4.0 \pm 0.5$ & $5 \cdot 0 \pm 0 \cdot 3$ \\
\hline
\end{tabular}

$+\mathrm{CM}=$ control multiparous, $\mathrm{TM}=$ treated multiparous, $\mathrm{CP}=$ control primiparous, $\mathrm{TP}=$ treated primiparous sows.

Values are mean \pm s.e.m.

$\ddagger$ Oestrus manifested during lactation.

${ }^{*}$ Multiparous sows were heavier $(P<0.05)$ at weaning than primiparous sows.

**Different from other treatment groups $(P<0.05)$. 
although CM sows tended $(P<0 \cdot 10)$ to have shorter intervals than TP sows (Table 1). Interval from treatment to oestrus in TM sows was similar to the interval from weaning to oestrus in the other 3 groups.

\section{Endocrine patterns before weaning}

From individual secretory patterns of each sow, average daily concentrations (average of 16 samples/day) of FSH and $\mathrm{LH}$ and FSH to $\mathrm{LH}$ ratios were calculated for each sampling day $(-1,0$, 1, 2 and 3) relative to $\mathrm{LS}+\mathrm{BE}$ (Fig. 1). Mean concentrations of FSH in serum were already 1.5fold higher $(P<0.01)$ in primiparous $(10.5 \pm 0.1 \mathrm{ng} / \mathrm{ml})$ than multiparous $(7 \cdot 1 \pm 0.1 \mathrm{ng} / \mathrm{ml})$ sows 1 day before LS + BE was started, and FSH was higher $(P<0.05)$ in TP $(12.4 \pm 1.4 \mathrm{ng} / \mathrm{ml})$ than TM $(5.9 \pm 0.9 \mathrm{ng} / \mathrm{ml})$ sows during Days $0-3$. In contrast to FSH, overall concentrations of $\mathrm{LH}$ were similar for primiparous $(0.4 \pm 0.05 \mathrm{ng} / \mathrm{ml})$ and multiparous $(0.5 \pm 0.04 \mathrm{ng} / \mathrm{ml})$ sows before start of treatment (Day -1$)$, whereas LH was higher $(P<0 \cdot 01)$ in TM $(0 \cdot 9 \pm 0 \cdot 1 \mathrm{ng} / \mathrm{ml})$ than CM $(0.4 \pm 0.1 \mathrm{ng} / \mathrm{ml})$ sows and greater $(P<0.05)$ in TP $(0.9 \pm 0.1 \mathrm{ng} / \mathrm{ml})$ than $\mathrm{CP}(0.4 \pm 0.1 \mathrm{ng} / \mathrm{ml})$ sows during treatment. Ratios of FSH to $\mathrm{LH}$ were 1.7 -fold higher $(P<0.05)$ in primiparous $(24 \cdot 2 \pm 3 \cdot 4)$ than multiparous $(14 \cdot 6 \pm 2 \cdot 4)$ sows before treatment (Day -1$)$, and FSH to LH ratios were greater $(P<0.05)$ in TP $(16 \cdot 1 \pm 1)$ than TM $(7 \cdot 6 \pm 0 \cdot 6)$ sows during Days $0-3$. Control sows $(\mathrm{CM}+\mathrm{CP})$ tended $(P<0 \cdot 10)$ to have higher FSH to LH ratios than did treated (TM $+\mathrm{TP})$ sows. Significant interactions $(P<0.001)$ of treatment $\times$ day for FSH to LH ratios are evident in Fig. 1. Gonadotrophin ratios declined or remained unchanged during LS + BE for treated sows (TP + TM), whereas FSH to LH ratios appeared to increase from Day 0 to Day 3 in controls (CP + CM). These patterns of ratios occurred as LH increased and FSH remained unchanged in treated sows compared with no change in LH in control sows (Fig. 1).

There were no differences between parities when pulse frequency and pulse amplitude of $\mathrm{LH}$ were compared on the day before treatment (data not shown). However, both frequency $(2 \cdot 0 \pm 0 \cdot 2$ vs $1.2 \pm 0.3$ pulses $/ 5 \mathrm{~h})$ and amplitude $(0.7 \pm 0.1$ vs $0.4 \pm 0.1 \mathrm{ng} / \mathrm{ml})$ of $\mathrm{LH}$ pulses were higher $(P<0.05)$ in TP than TM sows during LS + BE. Frequency of $\mathrm{LH}$ pulses was similar between TM and $\mathrm{CM}$ sows, whereas the pattern of LH pulses decreased across days for CP sows; they first decreased and then increased for TP sows. Magnitude and duration of $\mathrm{LH}$ pulses appeared to be unaffected by treatments, although duration of LH pulses increased 3- to 4-fold from Day - 1 to Day 0 in TP and TM sows.

Average daily pooled concentrations of oestradiol-17 $\beta$ (oestradiol), progesterone and cortisol in serum also are illustrated in Fig. 1 for all treatment groups on Days $-1,0,1,2$ and 3. Mean concentrations of oestradiol were already 2 -fold greater $(P=0.07)$ in multiparous than primiparous sows 1 day before LS + BE was begun. Oestradiol concentrations during treatment were higher $(P<0.05)$ in TM $(3.7 \pm 0.3 \mathrm{pg} / \mathrm{ml})$ than CM $(1.5 \pm 0.6 \mathrm{pg} / \mathrm{ml})$ sows, and higher $(P<0.01)$ in TM than TP $(1.3 \pm 0.4 \mathrm{pg} / \mathrm{ml})$ sows. In response to $\mathrm{LS}+\mathrm{BE}$, concentrations of oestradiol in TM sows increased $(P<0.05) 2$-fold from Day 0 to Day 3 (Fig. 1).

Average daily concentrations of progesterone in serum were similar between parities before treatment (Day -1$)$. However, average progesterone during treatment was higher $(P<0.01)$ in TP $(0.6 \pm 0.06 \mathrm{ng} / \mathrm{ml})$ than $\mathrm{CP}(0.3 \pm 0.09 \mathrm{ng} / \mathrm{ml})$ sows and higher $(P<0.05)$ in TM $(0.6 \pm 0.05 \mathrm{ng} / \mathrm{ml})$ than CM $(0.4 \pm 0.05 \mathrm{ng} / \mathrm{ml})$ sows. The peak increase in progesterone for treated sows (TP + TM) occurred on the 2nd day and not the 1st day of treatment. Progesterone in serum increased 3-fold from Day 0 to Day 1, and then decreased to initial (Day -1) concentrations by Day 3 for TP sows. In TM sows, progesterone increased 2.6-fold from Day 0 to Day 1 , and then declined by Day 3 to levels similar to those on Day 0 (Fig. 1).

Cortisol in serum was already higher $(P<0.05)$ for multiparous $(9.4 \pm 0.9 \mathrm{ng} / \mathrm{ml})$ than primiparous $(6.5 \pm 0.9 \mathrm{ng} / \mathrm{ml})$ sows before treatment initiation (Day -1$)$. Concentrations of cortisol were higher during treatment $(P<0.01)$ for TM $(17.0 \pm 0.8 \mathrm{ng} / \mathrm{ml})$ than $\mathrm{CM}(11.5 \pm 0.4 \mathrm{ng} / \mathrm{ml})$ sows and higher $(P<0.05)$ for TP $(17.6 \pm 1.2)$ than CP $(11.8 \pm 0.4 \mathrm{ng} / \mathrm{ml})$ sows. In contrast to 

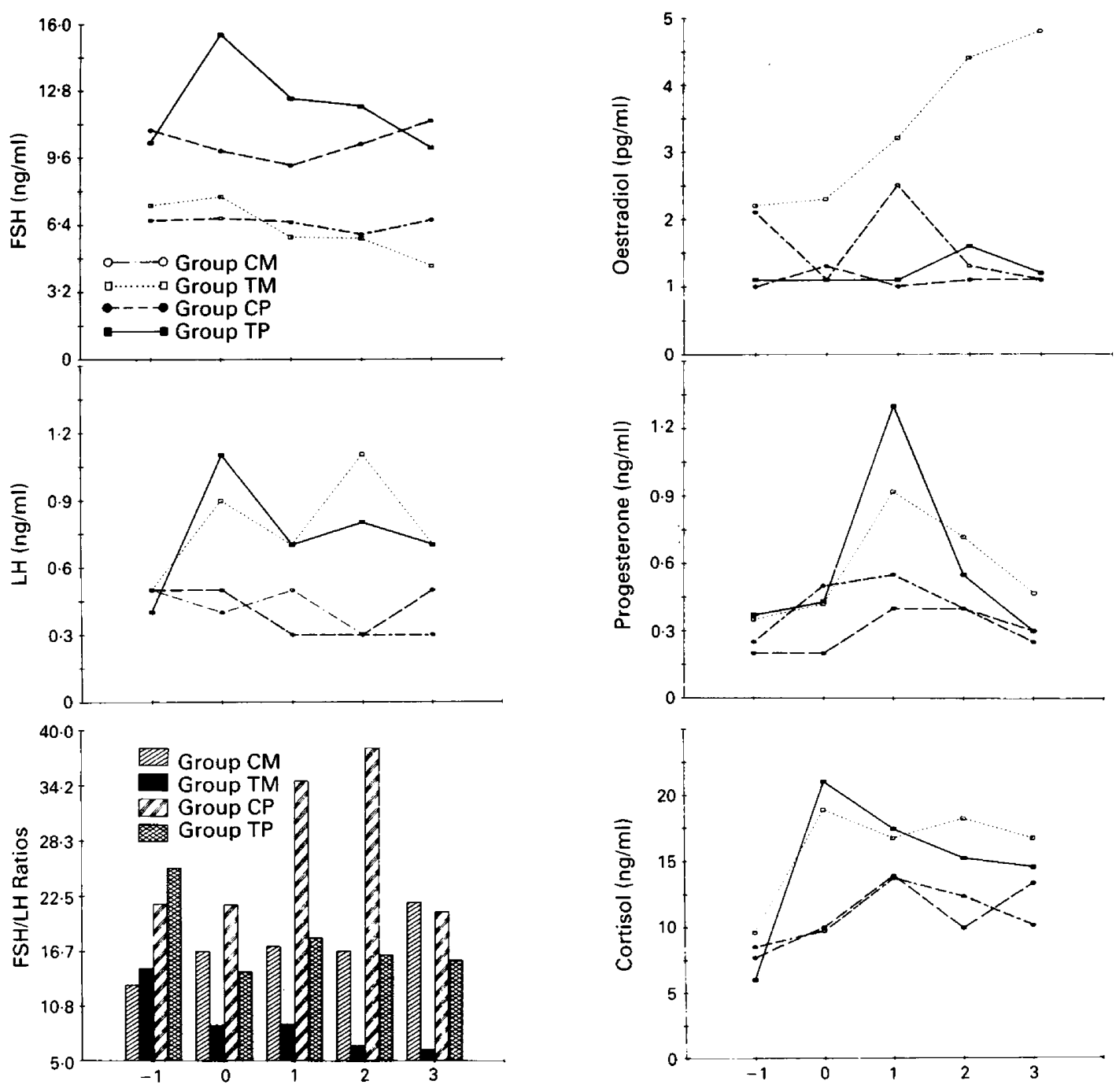

Days from LS + BE

Fig. 1. Mean concentrations of FSH, LH, FSH to LH ratios (average of 16 samples/day), oestradiol, progesterone and cortisol in serum in 4 treated primiparous (TP), 10 treated multiparous (TM), 2 control primiparous (CP), and 2 control multiparous (CM) sows relative to litter separation and boar exposure (Day 0 ). Standard errors ranged from 0.06 to 0.5 for FSH, 0.1 to 0.3 for $\mathrm{LH}, 0.6$ to 1.4 for $\mathrm{FSH} / \mathrm{LH}, 0.3$ to 0.6 for oestradiol, 0.02 to 0.1 for progesterone and 0.5 to 1.3 for cortisol.

changes in progesterone in response to treatment, peak cortisol in treated sows occurred on the 1st day of LS + BE (Day 0). A 2- to 3-5-fold increase in cortisol from Day - 1 to Day 0 was observed in treated (TM and TP) sows, but not for control sows (Fig. 1).

\section{Endocrine patterns after weaning}

From individual secretory patterns of each sow that had not expressed oestrus before weaning, overall daily concentrations (average of 16 samples/day) of FSH and LH, and FSH to LH ratios were 

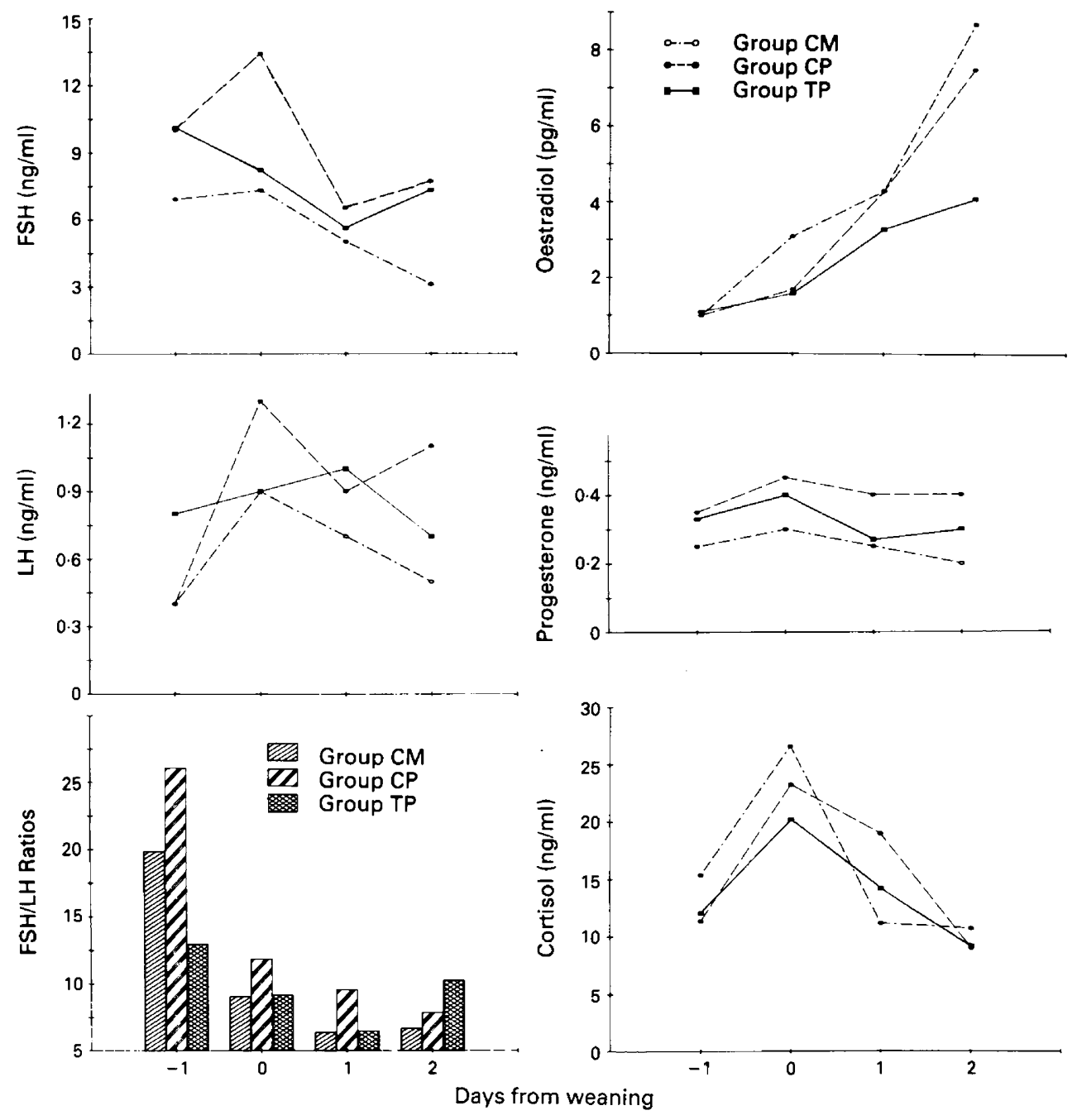

Fig. 2. Mean concentrations of FSH, LH, FSH to LH ratios (average of 16 samples/day), oestradiol, progesterone and cortisol in serum in 4 treated primiparous (TP), 2 control primiparous $(\mathrm{CP})$, and 2 control multiparous $(\mathrm{CM})$ sows relative to weaning (Day 0 ). Standard errors ranged from 0.1 to 0.2 for $\mathrm{FSH}, 0.07$ to 0.14 for $\mathrm{LH}$ and 0.8 to 1.1 for $\mathrm{FSH} / \mathrm{LH}, 0.07$ to 0.1 for oestradiol, 0.02 to 0.04 for progesterone and 1.4 to 2.5 for cortisol.

determined for each sampling day ( $-1,0,1$ and 2 ) relative to weaning (Fig. 2). Previous LS + BE treatment did not alter concentrations of FSH in TP sows, because CP and TP sows had similar patterns of FSH at weaning. Furthermore, FSH was higher in primiparous $(10 \cdot 0 \pm 0.2 \mathrm{ng} / \mathrm{ml})$ than multiparous $(6.9 \pm 0.2 \mathrm{ng} / \mathrm{ml})$ sows 1 day before weaning. A significant $(P<0.05)$ treatment $\times$ day interaction was detected for overall concentrations of FSH and probably was caused by a decrease in concentrations of FSH from Day 0 to Day 3 for CM sows, but not for CP or TP sows (Fig. 2).

Overall concentrations of $\mathrm{LH}$ in serum were similar in primiparous $(\mathrm{TP}+\mathrm{CP})$ sows $(0.4 \pm$ $0.1 \mathrm{ng} / \mathrm{ml})$ and multiparous $(\mathrm{CM})$ sows $(0.4 \pm 0.1 \mathrm{ng} / \mathrm{ml}) 1$ day before weaning (Fig. 2). Daily averages of $\mathrm{LH}$ were similar between treatment groups after weaning. However, within hours of weaning, LH nearly doubled in control sows, whereas TP sows showed no change (Fig. 2). Ratios of FSH to LH were similar for all groups on Days - 1, 0, 1 and 2 (Fig. 2). 
Before weaning, only amplitude and magnitude of $\mathrm{LH}$ pulses tended to be different between parities. Amplitude $(0.7 \pm 0.04 v s 0.5 \pm 0.08 \mathrm{ng} / \mathrm{ml})$ and magnitude of pulses of $\mathrm{LH}(1.1 \pm 0.1 \mathrm{vs}$ $0.7 \pm 0.16 \mathrm{ng} / \mathrm{ml})$ tended to be higher $(P<0.10)$ in primiparous than in multiparous sows, respectively. However, after weaning, the number of pulses of LH was 1.9 -fold higher $(P<0.05)$ in TP $(3.3 \pm 0.3$ pulses $/ 5 \mathrm{~h})$ and $\mathrm{CP}(2.2 \pm 0.5$ pulses $/ 5 \mathrm{~h})$ than in $\mathrm{CM}(1.3 \pm 0.5 \mathrm{pulses} / 5 \mathrm{~h})$ sows. In addition, frequency of pulses of LH tended $(P<0 \cdot 10)$ to be higher in TP than in CP sows. However, number of pulses of LH nearly doubled in TP sows from 2.7 to 4.3 pulses $/ 5 \mathrm{~h}$ from Day -1 to Day 0 , whereas change in pulse frequency for control sows on those days was not consistent. Baseline concentrations of LH and duration, magnitude, and amplitude of LH pulses were similar among treatment groups after weaning.

Mean daily concentrations of oestradiol, progesterone, and cortisol in serum after weaning also are illustrated in Fig. 2 for CM, CP and TP groups. Average concentrations of oestradiol were similar for all treatment groups 1 day before weaning, suggesting no effect of parity or age. Concentrations of oestradiol were 1.5 -fold higher $(P<0.05)$ for CP $(5.5 \pm 0.4 \mathrm{pg} / \mathrm{ml})$ than TP $(3.6 \pm 0.3 \mathrm{pg} / \mathrm{ml})$ sows after weaning. Oestradiol increased $(P<0.05)$ in a linear fashion from Day -1 to Day 2 from weaning in all sows (Fig. 2).

Pattern of progesterone in serum was similar for all treatment groups on Days $-1,0,1$ and 2 from weaning. Pattern of cortisol in serum was similar across treatment groups despite a numerical difference of 1.3-fold higher cortisol in serum of CP and TP sows compared to CM sows 1 day before weaning (Day - 1). Cortisol also was similar on Days 0,1 and 2 from weaning in all treatment groups. Concentrations of cortisol in serum increased $(P<0 \cdot 01) 2$-fold from Day -1 to Day 0 , and subsequently declined from Day 0 to Day 2 (Fig. 2).

\section{Discussion}

This study provides informtion about endocrine factors involved in stimulating oestrous cyclicity during and after lactation in sows. Our experiment was designed to investigate (1) the influences of litter separation and boar exposure on concentrations of hormones in serum responsible for inducing oestrus during lactation; (2) the differences in hormonal patterns between primiparous and multiparous sows in response to $\mathrm{LS}+\mathrm{BE}$ and weaning that may explain why primiparous sows have delayed intervals to oestrus after either treatment; and (3) the similarity between hormonal secretory patterns for sows that express oestrus during lactation in response to $\mathrm{LS}+\mathrm{BE}$ and those for sows that express oestrus after complete weaning.

Before treatment (LS + BE) was initiated during lactation, some differences in hormonal concentrations between primiparous and multiparous sows were evident. Concentrations of FSH in serum were higher in primiparous sows, whereas levels of cortisol and oestradiol were greater in multiparous than primiparous sows. Differences in FSH and oestradiol may partly reflect differences in ovarian follicular growth. No one study has compared follicular size of primiparous and multiparous sows during lactation. However, Kunavongkrit et al. (1982) reported a tendency towards increasing numbers of normal follicles $(2-5 \mathrm{~mm})$ during later stages of lactation in primiparous sows and Palmer et al. (1965), using second litter sows, observed follicles of the $\geq 5 \mathrm{~mm}$ size during most of lactation. Since a higher percentage of multiparous sows express oestrus during lactation in response to LS + BE (Stevenson \& Davis, 1984; Newton et al., 1987), it is possible that older sows have larger follicles that are more responsive to gonadotrophin stimulation. If this were the case one would expect that (1) the secretion of oestradiol would be greater in multiparous sows; and (2) the possible existence of negative feedback of some ovarian factor (possibly inhibin) on the secretion of FSH (Stevenson et al., 1981) would be greater in multiparous than primiparous sows. Both expectations were consistent with our data because oestradiol was greater and FSH was lower in multiparous sows.

Litter separation and boar exposure immediately increased concentrations of LH in treated compared with control sows. These data are similar to earlier reports in which weaning increased 
LH secretion (Aherne et al., 1976; Stevenson et al., 1981; Cox \& Britt, 1982a; Edwards \& Foxcroft, 1983; Kirkwood et al., 1984; Shaw \& Foxcroft, 1985). We also noted that frequency of pulses of LH were higher in TP than TM sows. Perhaps this reflects differences in age or parity for LH secretion and possibly is attributable to greater inhibition of $\mathrm{LH}$ by increased titres of oestradiol in TM sows.

Litter separation and boar exposure during lactation also affected concentrations of cortisol and progesterone in serum. Treatment resulted in an immediate increase in cortisol on Day 0 and a delayed increase in progesterone on Day 1 compared with control sows (Fig. 1). Increased concentrations of cortisol in serum of treated sows probably reflected response to physical movement, unfamiliar pens, and encounters with boars and other sows (Barnett et al., 1982). In addition, cortisol may have an adverse effect on secretion of LH during lactation and after weaning (Liptrap, 1970; Barb et al., 1982; Schilling \& von Rechenberg, 1983; Kunavongkrit, 1984). Increased progesterone in serum of treated sows on Day 1 after LS + BE may reflect an ovarian response to increased secretion of $\mathrm{LH}$. It is also possible that this increase in progesterone was an adrenal response to the stress of $\mathrm{LS}+\mathrm{BE}$. If so, we question why it was not observed on Day 0 concurrent with increased cortisol, rather than on Day 1 after LS + BE. Increased cortisol and progesterone may have inhibited follicular growth and (or) ovulation more in TP than TM sows, despite changes in LH. Perhaps the relatively inactive ovaries of TP sows, indicated by lower concentrations of oestradiol, were more sensitive to the inhibitory effects of elevated cortisol and progesterone and (or) less sensitive to gonadotrophin secretion than the ovaries of the TM sows.

Only multiparous (TM) sows exhibited oestrus during lactation; therefore, it was impossible to separate completely the responses to treatment and parity in our experiment (except on Day -1 from LS + BE or weaning) because the two factors were confounded. In our previous studies, about $45 \%$ of the primiparous sows and $76 \%$ of the multiparous sows were in oestrus during lactation after LS + BE (Stevenson \& Davis, 1984). All of our previous studies were conducted during winter (October to December), whereas this study was in May and we observed no oestrous response for primiparous sows in May and no response of primiparous or multiparous sows to LS + BE in August (Newton et al., 1987). Therefore, both season and parity may affect the response to $\mathrm{LS}+\mathrm{BE}$ during lactation. This relationship appears to be analogous to that which occurs after complete weaning. Season and parity have similar effects after weaning to those observed in our study for $\mathrm{LS}+\mathrm{BE}$, wherein primiparous sows have longer intervals from weaning to oestrus than older sows and this difference is exacerbated in summer and fall months (Rasbech, 1969; Aumaitre et al., 1976; Fahmy et al., 1979).

Reasons for fewer primiparous than multiparous sows becoming oestrous after LS + BE are not clear. However, differences in hormonal patterns between primiparous and multiparous sows in response to $\mathrm{LS}+\mathrm{BE}$ were mainly in the secretion of oestradiol and $\mathrm{FSH}$, oestradiol being greater in TM sows, and FSH higher in TP sows. Moreover, concentrations of oestradiol and FSH might reflect differences in ovarian follicular size between parities or differences in their sensitivity to serum gonadotrophins. Differences in follicular growth at weaning also may account for the differences in intervals to post-weaning oestrus between primiparous and multiparous sows that are commonly reported (Rasbech, 1969; Aumaitre et al., 1976; Fahmy et al., 1979; Hemsworth et al., 1982). Perhaps primiparous sows require more time for ovarian follicular development than do multiparous sows, resulting in increased intervals to oestrus.

Even though TP sows failed to come into oestrus during lactation, frequency of their LH pulses was greater and concentrations of $\mathrm{LH}$ and FSH tended to be greater than those of CP sows after weaning. However, no differences in these characteristics were observed before weaning (Day -1 , suggesting that TP sows experienced no carryover effects of the previous LS + BE treatment.

Sows resuming oestrous cyclicity during lactation appear to respond endocrinologically and physiologically as sows after weaning except that the exhibited oestrus during lactation generally required about 1 day longer after litter separation and boar exposure compared with sows of similar parity in oestrus after weaning. There were similarities of hormonal secretory patterns for sows that 
expressed oestrus during lactation (TM) or after weaning (CM, CP and TP sows). Concentrations of FSH in serum and FSH to LH ratios were relatively high 1 day before LS + BE (TM) and weaning (CM, CP, TP) and then decreased progressively over time (Figs 1 and 2). This changing pattern of the FSH to LH ratio suggests that an optimal combination of the two gonadotrophins is required to initiate the events leading to oestrus and ovulation in pigs (Shaw \& Foxcroft, 1985) as has been observed in women induced to ovulate with human chorionic gonadotrophin (Yuen et al., 1981). Pulsatile patterns of LH also appeared similar for sows in oestrus during lactation and after weaning, as did increases in baseline concentrations of LH. Cortisol in serum increased on the day of LS + BE (Day 0; Fig. 1) and weaning (Day 0; Fig. 2), and gradually decreased thereafter. Oestradiol increased progressively from Day 0 to Day 3 from LS + BE and weaning for all oestrous sows. The only reproductive hormone for which secretory patterns differed markedly following $\mathrm{LS}+\mathrm{BE}$ and after weaning was progesterone. Concentrations of progesterone in serum did not increase $24 \mathrm{~h}$ after weaning in CM, CP or TP sows, whereas they increased $24 \mathrm{~h}$ after the onset of $\mathrm{LS}+\mathrm{BE}$ for TM and TP sows. Cox \& Britt (1982b) reported that progesterone was elevated during lactation in sows treated with gonadotrophin-releasing hormone (GnRH) before and during oestrus, but this elevation did not interfere with oestrus or conception. Therefore, increased frequency of $\mathrm{LH}$ pulses during lactation may have elevated progesterone in the serum of our sows similar to those of Cox \& Britt (1982b), although the increased progesterone was short-lived (about $24 \mathrm{~h}$ ) and of lower magnitude (about $1 \mathrm{ng} / \mathrm{ml}$ ) compared with sows receiving $\mathrm{GnRH}$ pulses in the study of Cox \& Britt (1982b). The fact that TP sows failed to begin oestrous cycles during lactation in response to $\mathrm{LS}+\mathrm{BE}$ when progesterone, $\mathrm{LH}$ pulse frequency and increased concentrations of FSH were observed in serum is difficult to explain in view of the success of induced oestrus in GnRH-pulsed sows (Cox \& Britt, 1982b).

Coupled with the results from our previous work (Newton et al., 1987), it is suggested that (1) altering suckling patterns can induce oestrous cyclicity in lactating sows; (2) sows that respond to $\mathrm{LS}+\mathrm{BE}$ have hormonal secretory patterns similar to sows that return to oestrus after weaning (except for progesterone); (3) multiparous sows may have larger and (or) more gonadotrophinresponsive ovarian follicles and increased oestradiol secretion compared with primiparous sows, resulting in more multiparous sows being capable of expressing oestrus during lactation; and (4) increased secretion of progesterone and possibly cortisol during lactation might inhibit oestrous cyclicity in primiparous, but not multiparous, sows.

We thank T. Jewett, M. Trehan, M. Johnston at the Kansas State University Swine Teaching and Research Center and K. M. Parsons and E. M. Carpenter in our laboratory for assistance; L. Schinstock and K. Minneman for typing the manuscript; Dr Norman Mason for the oestradiol antiserum; Dr Leo Reichert for the purified FSH; and Dr Doug Bolt for the purified LH used for iodination and standards.

Contribution No. 87-97-J from the Kansas Agricultural Experiment Station, Manhattan, Kansas 66506, U.S.A.

\section{References}

Aherne, F.X., Christopherson, R.J., Thompson, J.R. \& Hardin, R.T. (1976) Factors affecting the onset of puberty, post-weaning estrus and blood hormone levels of Lacombe gilts. Can. J. Anim. Sci. 56, 68 I-692.

Aumaitre, A., Dagorn, J., Legault, C. \& LeDenmant, M. (1976) Influence of farm management and breed type on sows' conception-weaning interval and productivity in France. Livest. Prod. Sci. 3, 75-83.

Barb, C.R., Kraeling, R.R., Rampacek, G.B., Fonda, E.S. \& Kiser, T.E. (1982) Inhibition of ovulation and LH secretion in the gilt after treatment with ACTH or hydrocortisone. J. Reprod. Fert. 64, 85-92.

Barnett, J.L., Hemsworth, P.H. \& Cronin, G.M. (1982) The effect of mating on plasma corticosteroids in the female pig and the influence of individual and group penning on this response. Gen. comp. Endocr. 47, $516-521$.

Britt, J.H. (1986) Improving sow productivity through management during gestation, lactation and after weaning. J. Anim. Sci. 63, 1288-1296. 
Britt, J.H., Armstrong, J.D., Cox, N.M. \& Esbenshade, K.L. (1985) Control of follicular development during and after lactation in sows. J. Reprod. Fert., Suppl. $33,37-54$.

Cox, N.M. \& Britt, J.H. (1982a) Relationships between endogenous gonadotropin-releasing hormone, gonadotropins and follicular development after weaning in sows. Biol. Reprod. 27, 70-78.

Cox, N.M. \& Britt, J.H. (1982b) Pulsatile administration of gonadotropin releasing hormone to lactating sows: endocrine changes associated with induction of fertile estrus. Biol. Reprod. 27, 1126-1137.

Duggan, R.T., Bryant, M.J. \& Cunningham, F.J. (1982) Gonadotrophin, total oestrogen and progesterone concentrations in the plasma of lactating sows with particular reference to lactational oestrus. $J$. Reprod. Fert. 64, 303-313.

Edwards, W. \& Foxcroft, G.R. (1983) Endocrine changes in sows weaned at two stages of lactation. J. Reprod. Fert. 67, 161-172.

Esbenshade, K.L.; Vogel, M.J. \& Traywick, G.G. (1986) Clearance rate of luteinizing hormone and follicle stimulating hormone from peripheral circulation in the pig. J. Anim. Sci. 62, 1649-1653.

Fahmy, M.H., Holtmann, W.B. \& Baker, R.D. (1979) Failure to recycle after weaning and weaning to oestrus interval in crossbred sows. Anim. Prod. 29, 193-202.

Ford, J.J. \& Maurer, R.R. (1978) Simple technique for chronic venous catheterization of swine. Lab. Anim. Sci. 28, 615-618.

Gill, J.L. (1978) Design and Analysis of Experiments. Iowa State University Press, Ames.

Gill, J.L. \& Hafs, H.A. (1971) Analysis of repeated measurements of animals. J. Anim. Sci. 33, 331-336.

Hemsworth, P.H., Salden, N.T.C.J. \& Hoogerbrugge, A. (1982) The influence of the postweaning social environment on the weaning to mating interval of the sow. Anim. Prod. 35, 41-48.

Kirkwood, R.N., Lapwood, K.R., Smith, W.C. \& Anderson, L.L. (1984) Plasma concentrations of LH, prolactin, oestradiol-17 $\beta$ and progesterone in sows weaned after lactation for 10 or 35 days. J. Reprod. Fert. 70, 95-102.

Kluber E.F., III, Pollmann, D.S., Davis, D.L. \& Stevenson, J.S. (1985) Body growth and testicular characteristics of boars fed a synthetic progestogen, altrenogest. $J$. Anim. Sci. 61, 1441-1447.

Kraeling, R.R., Rampacek, G.B. \& Cox, N.M. (1982) Prolactin and luteinizing hormone secretion after bromocryptine (CB-154) treatment in lactating sows and ovariectomized gilts. J. Anim. Sci. 54, 1212-1220.

Kunavongkrit, A. (1984) Clinical, morphological and endocrinological studies in primiparous postpartum sows. Ph.D. thesis, Svergies Lantbruksuniversitet, Uppsala, Sweden.

Kunavongkrit, A., Einarsson, S. \& Settergren, I. (1982) Follicular development in primiparous lactating sows. Anim. Reprod. Sci. 5, 47-56.

Liptrap, R.M. (1970) Effects of corticotrophin and corticosteroids on oestrus, ovulation and oestrogen excretion in the sow. J. Endocr. 47, 197-205.
McLeod, B.J., Haresign, W. \& Lamming, G.E. (1982) The induction of ovulation and luteal function in seasonally anoestrous ewes treated with small-dose multiple injections of GnRH. J. Reprod. Fert. 65, 215-221.

Newton, E.A., Stevenson, J.S. \& Davis, D.L. (1987) Influence of duration of litter separation and boar exposure on estrous expression of sows during and after lactation. J. Anim. Sci. 65, in press.

NRC (1979) Nutrient Requirements of Domestic Animals: No. 2, Nutrient Requirements of Swine, 8th Revised edn. National Academy of Sciences-National Research Council, Washington, D.C.

Palmer, W.M., Teague, H.S. \& Venzke, W.G. (1965) Macroscopic observations on the reproductive tract of the sow during lactation and early postweaning. $J$. Anim. Sci. 24, 541-545.

Parvizi, N., Elsaesser, F., Smidt, D. \& Ellendorff, F. (1976) Plasma LH and progesterone in the adult female pig during the oestrous cycle, late pregnancy and lactation, and after ovariectomy and pentobarbitone treatment. J. Endocr. 69, 193-203.

Rasbech, N.O. (1969) A review of the causes of reproductive failure in swine. $B r$. vet. $J .125,599-616$.

Riley, G.M., Peters, A.R. \& Lamming, G.E. (1981) Induction of pulsatile $\mathrm{LH}$ release and ovulation in post-partum acyclic beef cows by repeated small doses of Gn-RH. J. Reprod. Fert. 63, 559-565.

Rowlinson, P. \& Bryant, M.J. (1981) Lactational oestrus in the sow. 1. The effect of the interval between farrowing and grouping on the incidence and timing of lactational oestrus in sows. Anim. Prod. 32, 315-323.

Rowlinson, P. \& Bryant, M.J. (1982) Lactational oestrus in the sow. 2. The influence of group-housing, boar presence and feeding level upon the occurrence of oestrus in lactating sows. Anim. Prod. 34, 283-290.

SAS (1982) SAS Users's Guide: Statistics. Statistical Analysis System Institute, Inc., Cary, NC.

Schilling E. \& von Rechenberg, W. (1983) Function of the adrenal cortex and the process of ovulation in the pig. Zentbl. VetMed. A 20, 705-717.

Shaw, H.J. \& Foxcroft, G.R. (1985) Relationships between $\mathrm{LH}, \mathrm{FSH}$ and prolactin secretion and reproductive activity in the weaned sow. $J$. Reprod. Fert. $75,17-28$.

Stevenson, J.S. \& Davis, D.L. (1984) Influence of reduced litter size and daily litter separation on fertility of sows at 2 to 5 weeks postpartum. J. Anim. Sci. 59, 284-293.

Stevenson, J.S., Cox, N.M. \& Britt, J.H. (1981) Role of the ovary in controlling $\mathrm{LH}, \mathrm{FSH}$ and prolactin secretion during and after lactation in pigs. Biol. Reprod. 24, $341-353$.

Yuen, B.H., Sy, L. \& Cannon, W. (1981) Regulation of ovarian follicular and luteal function during treatment with exogenous gonadotropins in anovulatory infertility. Am. J. Obstet. Gynec. 140, 629 635 . 